\title{
Aglutininas anti-leptospira em jumentos nordestinos criados na microrregião de Patos, Paraíba, Brasil no período de 1996 a 1997
}

\section{Anti-leptospire Agglutinines levels in donkeys of northeastern farm of Patos, Paraíba, Brazil during the year 1996 to 1997} Vandecleide Rodrigues de Lima, ${ }^{*}$ Clebert José Alves, ${ }^{* \star}$ Sílvio Arruda Vasconcellos, ${ }^{\star \star \star}$ Zenaide Macedo de Morais, ${ }^{\star * \star \star}$
Josué Oliveira Moreira*

\section{Resumo}

Tendo em vista a escassez de informações científicas nas mais diversas áreas do conhecimento (Produção Animal, Reprodução e Sanidade Animal) e, mediante a importância da leptospirose como infecção transmissível entre os animais e o homem, foi investigada a presença de aglutininas antileptospiras em jumentos criados na região semi-árida de Patos, Paraíba, associando-se os resultados a possíveis perturbações na esfera reprodutiva. Amostras de soro sangüíneo de 90 jumentos foram submetidas à avaliação através da técnica de soroaglutinação microscópica (SAM) aplicada à leptospirose, com utilização de 24 sorotipos (australis, bratislava, autumnalis, butembo, castellonis, bataviae, canicola, whitcombi, cynopteri, grippotyphosa, hebdomadis, copenhageni, icterohaemorrhagiae, javanica, panama, pomona, pyrogenes, hardjo, wolffi, shermani, tarassovi, sentot, andamana e patoc), obtendo-se como resultado de aglutinação os sorotipos australis, pyrogenes, pomona, icterohaemorrhagiae e castellonis, com predominância para o australis. A análise estatística, utilizando o programa EPIDAT 1.0, segundo o teste de Qui-Quadrado com nível de significância de $5 \%$, não revelou diferenças significativas entre as variáveis estudadas.

Palavras-chave: leptospirose; jumentos; aglutininas; soroaglutinação.

\section{Introdução}

A leptospirose é uma doença bacteriana que acomete os animais domésticos e o homem, cujo agente etiológico é uma espiroqueta pertencente à Ordem Spirochaetales, Família Leptospiraceae, Gênero Leptospira constituído pelas espécies Leptospira interrogans, L. borgpetersenii, L. weilli, L. noguchii, L. santarosai, L. kirchnerie L. feini. Esta doença tem assumido grande importância, tanto nos países em desenvolvimento quanto nos desenvolvidos, afetando a saúde animal (Alves, 1996 e 1997; Blenden, 1975; Faine, 1982; Guimarães et al.,1982/1983; Hanson, 1977; Michina, 1970; Szyfres, 1975), a economia da produção, a saúde pública (Centro Panamericano de Zoonoses, 1985; Côrtes, 1993) e a disponibilidade de proteína animal para a população humana, como relatam Abdussalam (1975), Bernard (1993), Costa et al. (1986), Correa et al. (1972) e Monke (1975).

A ocorrência da leptospirose é variável, podendo-se observar tanto as formas esporádicas quanto a endêmica. Os surtos se reproduzem por exposição a água contaminada com a urina ou tecidos provenientes de animais infectados (Correa et al., 1972). Uma vez em contato com a pele lesada ou a mucosa do hospedeiro susceptível, as leptospiras ganham a corrente circulatória e inicia-se a fase de multiplicação do agente no sangue e diversos órgãos afins, como fígado, baço e rins. Este é o período de leptospiremia (Davidson, 1971; Guimarães et al., 1982/1983; Turner, 1967; Vasconcellos, 1987) que tem uma duração média de quatro a cinco dias, raramente ultrapassando sete dias.

Quando o animal consegue superar a fase aguda da infecção, o seu sistema imune reage, produzindo anticorpos que antagonizam as leptospiras, presentes nos diversos humores, tecidos e órgãos e faz com que as mesmas persistam apenas em algumas áreas do organismo aonde os anticorpos ocorrem em baixos níveis, como é o caso da luz dos túbulos renais (Turner, 1967).

O modelo de evolução da infecção onde a leptospirúria se estabelece após uma fase aguda com sintomatologia evidente caracteriza a modalidade de fonte de infecção referida como portador convalescente. Entretanto, em surtos

\footnotetext{
*Universidade Federal da Paraíba, CSTR, Departamento de Medicina Veterinária, Campus VII, Patos, PB, Brasil - Bolsista IC / CNPq.

**Universidade Federal da Paraíba, CSTR, Departamento de Medicina Veterinária, Campus VII, Patos, PB, Brasil.

***FMVZ, Universidade de São Paulo (USP), São Paulo - SP, Brasil.

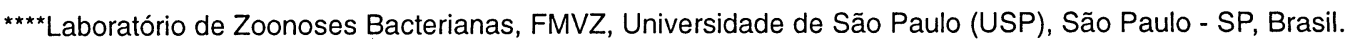


de leptospirose nos rebanhos de interesse econômico é comum a existência de indivíduos que apresentam uma fase aguda assintomática, entrando no período de leptospirúria, inclusive sem demonstrar a presença de anticorpos. Esta última situação representa a modalidade de fonte de infecção definida como "portador são" que, por ser de difícil identificação, assume importância destacada em termos de saúde animal e de saúde pública (Turner, 1967; Vasconcellos, 1993).

Em virtude da carência de investigações científicas realizadas nos jumentos explorados na Região Nordeste do Brasil e em face da grande importância que a leptospirose assume como infecção de caráter zoonótico que freqüentemente acomete os animais sob a forma inaparente, representando, por conseguinte, um risco potencial para a saúde pública bem como significativas perdas econômicas, foi estruturado o presente trabalho que teve por objetivo pesquisar a ocorrência de aglutininas antileptospira em jumentos nordestinos criados em condições semi-áridas.

\section{Material e métodos}

Animais: foram utilizados na investigação 30 jumentos nordestinos agrupados conforme a variedade em cardans, pretos e roxos.

Propriedade: os animais foram trabalhados na Fazenda Lameirão, pertencente à Universidade Federal da Paraíba/ Centro de Saúde e Tecnologia Rural/Campus VII/Patos-PB.

Colheitas: foram efetuadas três colheitas de sangue, durante o ano de 1996 e 1997, seguindo uma metodologia preestabelecida que as distribuiu da seguinte forma: período I (julho/agosto), período II (novembro/dezembro) e período III (março/abril).

As amostras de sangue foram obtidas por punção da veia jugular com seringas descartáveis; o sangue foi transferido para frascos estéreis, os quais foram enviados para o Laboratório de Doenças Transmissíveis do Centro de Saúde e Tecnologia Rural da Universidade Federal da Paraíba, onde foi realizado o dessoramento e congelamento das amostras a $20^{\circ} \mathrm{C}$ negativos. As amostras de soro sangüíneo foram submetidas à pesquisa de aglutininas antileptospira no Laboratório de Zoonoses Bacterianas do Departamento de Medicina Veterinária Preventiva e Saúde Animal da Faculdade de Medicina Veterinária e Zootecnia/Universidade de São Paulo.

Microtécnica de Soroaglutinação Microscópica: seguiu a metodologia preconizada por Galton et al. (1965), utilizando-se uma coleção de antígenos vivos pertencente ao laboratório de Zoonoses Bacterianas da Faculdade de Medi- cina Veterinária e Zootecnia da Universidade de São Paulo, contendo 22 variantes sorológicas de leptospiras patogênicas (australis, bratislava, autumnalis, butembo, castellonis, bataviae, canicola, whitcombi, cynopteri, grippotyphosa, hebdomadis, copenhageni, icterohaemorrhagiae, javanica, panama, pomona, pyrogenes, hardjo, wolffi, shermani, tarassovi, sentot) e duas variantes de leptospiras saprófitas (andamana e patoc). Os soros foram triados na razão 100 e os que apresentaram resultado positivo foram titulados em uma série de diluições geométricas de razão dois. A variante sorológica considerada foi a que apresentou maior título.

Tratamento estatístico: foi realizado utilizando-se o programa EPIDAT 1.0, segundo o teste não-paramétrico de Qui-Quadrado. O nível de significância adotado foi de $5 \%$.

\section{Resultados}

Na Tabela 1 são apresentados os resultados dos exames dos soros sangüíneos dos jumentos nordestinos examinados através da microtécnica de soroaglutinação microscópica (SAM), segundo o momento da colheita e a natureza do resultado.

Tabela 1: Jumentos nordestinos da Propriedade Lameirão, localizada na microrregião de Patos, examinados pela microtécnica de soroaglutinação microscópica (SAM) aplicada à leptospirose, segundo o momento da colheita do soro sangüíneo e a natureza do resultado. Paraíba, 1997.

\begin{tabular}{|c|c|c|c|c|}
\hline \multicolumn{5}{|c|}{ ÉPOCA DA COLHEITA } \\
\hline Reatores & $\begin{array}{c}1^{\mathrm{a}} \text { colheita } \\
\text { (jul./ago./96) }\end{array}$ & $\begin{array}{c}2^{\mathrm{a}} \text { colheita } \\
\text { (nov./dez./96) }\end{array}$ & $\begin{array}{c}3^{\mathrm{a}} \text { colheita } \\
\text { (mar./abr./97) }\end{array}$ & Total \\
\hline Sim & 06 & 05 & 11 & 22 \\
\hline Não & 24 & 25 & 19 & 68 \\
\hline Total & 30 & 30 & 30 & 90 \\
\hline
\end{tabular}

Qui-Quadrado observado: 3,71

Qui-Quadrado crítico para a de 5\% (5 de liberdade): 5,99

A Tabela 2 apresenta os resultados dos exames dos soros sangüíneos dos jumentos nordestinos pesquisados através da microtécnica de soroaglutinação microscópica (SAM), segundo a época do ano e o sorotipo reator. Observa-se nesta tabela que o sorotipo encontrado com maior freqüência foi o australis, seguido logo após pelo icterohaemorrhagiae.

A análise estatística, utilizando o programa EPIDAT 1.0, através do teste de Qui-Quadrado, não revelou diferenças significativas entre as variáveis estudadas. 
Tabela 2: Resultados de exames de soro sangüíneo de jumentos nordestinos através da microtécnica de soroaglutinação microscópica (SAM) aplicada à leptospirose, segundo a época do ano e o sorotipo reator. Colheitas efetuadas no período de julho de 1996 a abril de 1997.

\begin{tabular}{|c|c|c|c|c|c|c|}
\hline \multirow{3}{*}{$\begin{array}{c}\text { Sorotipo } \\
\text { Reator }\end{array}$} & \multicolumn{6}{|c|}{ ÉPOCA DO ANO } \\
\hline & \multicolumn{2}{|c|}{$\begin{array}{c}1^{\mathrm{a}} \text { colheita } \\
\text { (jul./ago./96) }\end{array}$} & \multicolumn{2}{|c|}{$\begin{array}{c}2^{\mathrm{a}} \text { colheita } \\
\text { (nov./dez./96) }\end{array}$} & \multicolumn{2}{|c|}{$\begin{array}{c}3^{\mathrm{a}} \text { colheita } \\
\text { (mar./abr./97) }\end{array}$} \\
\hline & $\mathrm{N}^{0}$ & $\%$ & $\mathrm{~N}^{\circ}$ & $\%$ & $\mathrm{~N}^{\circ}$ & $\%$ \\
\hline australis & 04 & 66,67 & 04 & 80,00 & 06 & 54,55 \\
\hline bratislava & $\ldots$ & $\ldots$ & $\ldots$ & $\ldots$ & $\cdots$ & $\ldots$ \\
\hline autumnalis & $\cdots$ & $\cdots$ & $\ldots$ & $\ldots$ & $\ldots$ & $\cdots$ \\
\hline butembo & $\ldots$ & $\ldots$ & $\ldots$ & $\ldots$ & $\ldots$ & $\ldots$ \\
\hline castellonis & $\ldots$ & $\ldots$ & $\ldots$ & $\ldots$ & 01 & 9,09 \\
\hline bataviae & $\ldots$ & $\ldots$ & $\ldots$ & $\ldots$ & $\ldots$ & $\ldots$ \\
\hline canicola & $\ldots$ & $\ldots$ & $\ldots$ & $\ldots$ & $\ldots$ & $\ldots$ \\
\hline whitcombi & $\ldots$ & $\ldots$ & $\ldots$ & $\ldots$ & $\ldots$ & $\ldots$ \\
\hline cynopteri & $\ldots$ & $\ldots$ & $\ldots$ & $\ldots$ & $\ldots$ & $\ldots$ \\
\hline grippotyphosa & $\cdots$ & $\ldots$ & $\cdots$ & $\cdots$ & $\ldots$ & $\cdots$ \\
\hline hebdomadis & $\ldots$ & $\ldots$ & $\ldots$ & $\ldots$ & $\ldots$ & $\ldots$ \\
\hline copenhageni & $\ldots$ & $\ldots$ & $\ldots$ & $\ldots$ & $\ldots$ & $\ldots$ \\
\hline icterohaemorrhagiae & 02 & 33,33 & $\ldots$ & $\ldots$ & 02 & 18,18 \\
\hline javanica & $\ldots$ & $\ldots$ & $\ldots$ & $\ldots$ & $\ldots$ & $\ldots$ \\
\hline panama & $\ldots$ & $\ldots$ & $\ldots$ & $\ldots$ & $\ldots$ & $\ldots$ \\
\hline pomona & $\ldots$ & $\ldots$ & $\ldots$ & $\ldots$ & 02 & 18,18 \\
\hline pyrogenes & $\ldots$ & $\ldots$ & 01 & 20,00 & $\ldots$ & $\ldots$ \\
\hline hardjo & $\ldots$ & $\ldots$ & $\ldots$ & $\ldots$ & $\ldots$ & $\ldots$ \\
\hline wolffi & $\ldots$ & $\ldots$ & $\ldots$ & $\ldots$ & $\ldots$ & $\ldots$ \\
\hline shermani & $\ldots$ & $\ldots$ & $\ldots$ & $\ldots$ & $\ldots$ & $\ldots$ \\
\hline tarassovi & $\ldots$ & $\ldots$ & $\ldots$ & $\ldots$ & $\ldots$ & $\cdots$ \\
\hline andamana & $\ldots$ & $\ldots$ & $\ldots$ & $\ldots$ & $\ldots$ & $\ldots$ \\
\hline patoc & $\ldots$ & $\ldots$ & $\ldots$ & $\ldots$ & $\ldots$ & $\ldots$ \\
\hline sentot & $\ldots$ & $\ldots$ & $\ldots$ & $\ldots$ & $\ldots$ & $\ldots$ \\
\hline Total & 06 & 100,0 & 05 & 100,0 & 11 & 100,0 \\
\hline
\end{tabular}

\section{Discussão}

A análise dos resultados obtidos permite constatar a presença de animais soro-reatores, demonstrados nas tabelas 1 e 2 .

A caracterização dos sorotipos mais freqüentes apresentados na Tabela 2 , revela que a variante sorológica australis destacou-se em relação aos demais sorotipos, em todas as colheitas realizadas, porém apresentou um maior número de casos positivos na terceira colheita (março/abril 97), divergindo dos dados encontrados por Abuchaim (1991) que obteve o sorotipo icterohaemorrhagiae como mais prevalente em eqüinos do
Estado do Rio Grande do Sul. O sorotipo icterohaemorrhagiae, foi o segundo mais freqüente neste trabalho, tendo sido encontrado na primeira (julho/agosto - 96) e terceira (março/abril - 97) colheitas. Destaca-se ainda na Tabela 2, a presença de outros sorotipos, tais como pyrogenes, pomona e castellonis, podendo-se observar, sobretudo, que a predominância dos animais soro-reatores ocorreu no período de março/abril de 1997, período no qual acontece o inverno no semi-árido nordestino. Este fato sugere que, mesmo sob condições de clima semi-árido, a possibilidade de disseminação da leptospirose é ampliada com o aumento do índice pluviométrico.

Em inquérito sorológico realizado em eqüinos atendidos pelo Hospital Veterinário da Universidade Federal da Paraíba/ Centro de Saúde e Tecnologia Rural/ Campus VII/Patos-PB, Alves (1997) constatou que, de 39 amostras de soro sangüíneo avaliadas pela técnica de soroaglutinação microscópica (SAM), foram prevalentes os sorotipos: pyrogenes, patoce hardjo. Neste particular, comparando-se a pesquisa de aglutininas antileptospira entre eqüinos e jumentos nordestinos criados no semi-árido, foi possível identificar o sorotipo pyrogenes com freqüência em ambas as espécies. Ressalte-se, ainda, que os dados obtidos aqui divergem dos referidos por Bernard (1993), que destacam o sorotipo bratislava como o mais prevalente em eqüinos examinados na Irlanda.

Com relação à associação da leptospirose a perturbações na esfera reprodutiva, não foi constatado nenhum evento clínico que indicasse a presença da doença. Os dados revelados nas Tabelas 1 e 2 permitem sugerir que o jumento nordestino desenvolva a forma inaparente da leptospirose em seu ambiente, constituindo-se, assim, em um portador e, conseqüentemente, importante fonte de infecção para o homem e demais animais domésticos que com ele convivem.

\section{Conclusão}

A avaliação dos dados obtidos permitiram constatar a presença de aglutininas antileptospira em jumentos nordestinos criados no semi-árido brasileiro. 


\section{Abstract}

The donkey of northeastern Brazil is a domesticated animal of importance in the areas that presents resistance to the climatic conditions of this Brazilian semi-arid region. The livel of scientific information in the most areas of the exploration of these animals (Animal Production, Reproduction and Animal Sanity) and, by means of the importance of the leptospirosis as transmissible infection between the animals and the man, the investigation of the presence of aglutininas antileptospires was done in donkeys of semi-arid area of Patos, Paraíba/Brasil. Associations between serological results and occurence of disturbances in the reproductive sphere was performed. The blood samples which were submitted to the evaluation by the microtechnique of microscopic agglutination (S.A.M) applied to the leptospirosis, birth 24 serovars (australis, bratislava, autumnalis, butembo, castellonis, bataviae, canicola, whitcombi, cynopteri, grippotyphosa, hebdomadis, copenhageni, icterohaemorrhagiae, javanica, panama, pomona, pyrogenes, hardjo, wolffi, shermani, tarassovi, sentot, andamana e patoc), being obtained as result the presence of several serovars, the ones which, australis, pyrogenes, pomona, hardjo, icterohaemorrhagiae and wolffi, with predominance for the serovar australis. The statistical analysis, using the program EPIDAT 1.0, according to the test of Qui-square with level of significance of $5 \%$, did not reveal significant differences among the studied variables.

Keywords: leptospirosis; donkeys; antibodies; agglutinines.

\section{Referências bibliográficas}

ABUCHAIM, D. M. Presença de aglutininas antileptospira em soro de eqüinos no Estado do Rio Grande do Sul. Arq. Fac. Vet. UFRGS, Porto Alegre, v.19, p. 9-14, 1991.

ABDUSSALAM, M. 1975. Situación mundial del problema de la leptospirose In: Reunión Interamérica sobre el Control de la Fiebre Aftosa y otras Zoonosis. 8.ed. Organização Mundial de Saúde, Guatemala, p. 142-153 (publicación científica, 316).

ALVES, C. J. Pesquisa de aglutininas antileptospira em eqüinos criados no semi-árido nordestino. Patos: Universidade Federal da Paraíba/Campus VII (trabalho não publicado), 1997.

Influência de fatores ambientais sobre a proporção de caprinos sororreatores para a leptospirose em cinco centros de criação do estado da Paraíba. n. 2. Arq. Inst. Biol., São Paulo, 63, p. 11-18, 1996.

BERNARD, W. V. Leptospirosis. Update on infections diseases. oㅡ. Aug, North America, 9, p. 435-445, 1993.

BLENDEN, D.C. Aspectos epidemiológicos de la leptospirosis. In: Reunión Interamérica sobre el Control de la Fiebre Aftosa y otras Zoonosis. 8. ed. Organização Mundial de Saúde, Guatemala: p. 142-153 (publicación científica, 316), 1975.

CENTRO PANAMERICANO DE ZOONOSIS. Manual sobre Métodos de Laboratório para Leptospirose. Buenos Aires: 46 p. (Nota Técnica n. 30), 1985.

CÔRTES, J. A. Aspectos epidemiológicos e ecológicos da leptospirose. Anais do Encontro Nacional em Leptospirose. 3. ed. Rio de Janeiro: Ministério da Saúde/FIOCRUZ, p. 53-57, 1993.

COSTA, A. F. P., SANTA ROSA, C. A., ALMEIDA, W.F., TROISE, C. Pesquisa de aglutininas anti-leptospira entre magarefes em alguns municípios do estado de São Paulo. Revista do Instituto de Medicina Tropical, São Paulo, n. 8, p. 287-290, 1986.

CORREA, M. O.A., HYSKUTARE, S., AZEVEDO, R. Considerações sobre novo surto epidêmico de leptospirose na cidade do Recife em 1970. Revista do Instituto Adolfo Lutz 32, p. 83-87, 1972.
DAVIDSON, K. R. Leptospirosis hardjo infection in man associated with an outbreak in a dairy herd. Australian Veterinary Journal 47, 408 p., 1971.

FAINE, S. Guidelines for the control of leptospirosis. Geneva: World Health Organizacion, 171 p. (who off set Publication, 67), 1982.

GALTON, M. M., SULZER, C. R., SANTA ROSA, C. A., FIELDS, M. J. Aplication of a microtechnique to the agglutination test leptospiral antibodies. Appl. Microbiol. 13, p. 81-85, 1965.

GUIMARÃES, M.C., CÔRTES, J.A., VASCONCELLOS, S. A., ITO, F. H. Epidemiologia e controle da leptospirose em bovinos: papel do portador e seu controle terapêutico. Comunicações Científicas da Faculdade de Medicina Veterinária e Zootecnia da Universidade de São Paulo 6/7, p. 21-34, 1982/ 1983.

HANSON, L. E. Imunology of bacterial diseases, with special reference to leptospirosis. J Am Med Assoc, 170, p. 991994, 1977.

MICHINA, S. W. Leptospirosis. Veterinary Record, n. 86, p. 484-496, 1970.

MONKE, D. R. Leptospirosis, with special interest in bulls. Advances in Animal Breeding 26, p. 10-14, 1975.

SZYFRES, B. 1975. La leptospirose como problema de salud humana y animal en América Latina y el area del Caribe. In: Reunión Interamérica sobre el Control de la Fiebre Aftosa y otras Zoonosis 8. ed. Organização Mundial de Saúde, Guatemala: p. 125-141 (Publicación Científica, 316).

TURNER, L. H. Leptospirosis I. Trans Roy Soc Trop Med Hyg 61, p. 842-855, 1967.

VASCONCELLOS, S. A. Leptospirose animal. Anais do Encontro Nacional em Leptospirose, 3. Rio de Janeiro: Ministério da Saúde/FIOCRUZ, p. 62-66, 1993.

O papel dos reservatórios na manutenção de leptospiras na natureza. Comunicações Científicas da Faculdade Medicina Veterinária e Zootecnia da Universidade de São Paulo 11, p. 17-24, 1987. 